\title{
Environmental insults in early life and submissiveness later in life in mouse models
}

\author{
Seico Benner ${ }^{1}$, Toshihiro Endo ${ }^{1,2}$, Masaki Kakeyama ${ }^{1,3 *}$ and Chiharu Tohyama ${ }^{1 *}$ \\ 'Laboratory of Environmental Health Sciences, Center for Disease Biology and Integrative Medicine, Graduate School of \\ Medicine, The University of Tokyo, Tokyo, Japan, ${ }^{2}$ Department of Neurochemistry, Graduate School of Medicine, The \\ University of Tokyo, Tokyo, Japan, ${ }^{3}$ Department of Neurobiology and Behavior, Nagasaki University, Nagasaki, Japan
}

\section{OPEN ACCESS}

Edited by:

Sonoko Ogawa

University of Tsukuba, Japan

Reviewed by:

Fumihiko Maekawa

National Institute for Environmental

Studies, Japan

Daniel Wagner Hamada Cohn,

University of São Paulo, Brazil

*Correspondence:

Masaki Kakeyama,

Department of Neurobiology and

Behavior, Graduate School of

Biomedical Sciences, Nagasaki

University, 1-12-4 Sakamoto,

Nagasaki 852-8523, Japan

kakeyama@nagasaki-u.ac.jp;

Chiharu Tohyama,

Laboratory of Environmental Health

Sciences, Center for Disease Biology and Integrative Medicine,

Graduate School of Medicine, The University of Tokyo, 7-3-1 Hongo,

Tokyo 113-0033, Japan

mtohyama@mail.ecc.u-tokyo.ac.jp

Specialty section:

This article was submitted to Neuroendocrine Science, a section of the journal Frontiers in Neuroscience

Received: 17 September 2014 Accepted: 04 March 2015 Published: 31 March 2015

Citation:

Benner S, Endo T, Kakeyama M and

Tohyama C (2015) Environmental insults in early life and submissiveness later in life in mouse models.

Front. Neurosci. 9:91. doi: 10.3389/fnins.2015.00091
Dominant and subordinate dispositions are not only determined genetically but also nurtured by environmental stimuli during neuroendocrine development. However, the relationship between early life environment and dominance behavior remains elusive. Using the IntelliCage-based competition task for group-housed mice, we have previously described two cases in which environmental insults during the developmental period altered the outcome of dominance behavior later in life. First, mice that were repeatedly isolated from their mother and their littermates (early deprivation; ED), and second, mice perinatally exposed to an environmental pollutant, dioxin, both exhibited subordinate phenotypes, defined by decreased occupancy of limited resource sites under highly competitive circumstances. Similar alterations found in the cortex and limbic area of these two models are suggestive of the presence of neural systems shared across generalized dominance behavior.

Keywords: dominance behavior, social behavior, early life environment, IntelliCage-based competition task, mouse

\section{Introduction}

Social dominance is a universal behavioral feature exhibited by social animals across species and is considered one of the few robust and reliable social behavior indices in experimental animals. Dominance behavior is exhibited primarily in competitive situations, where individuals with tendencies to dictate to others are referred to as dominant, whereas those being dictated to are referred to as subordinates (Rowell, 1974). Generally, dominant individuals gain priority of access to resources and copulation (Dewsbury, 1982; Akbaripasand et al., 2014), reflecting the ecological significance of social dominance.

Numerous intrinsic factors are thought to be involved in generating dominance behavior, such as levels of aggressiveness and anxiety (Chase et al., 2002), and dominance behavior has been used as an indicator to study affective disorders in experimental animals (Malatynska and Knapp, 2005). Although there is a substantial genetic influence determining these intrinsic characteristics (Braw et al., 2006; Malkesman et al., 2006; Babri et al., 2014), the development of social behavioral disposition is presumably nurtured by the environment as well. In particular, social environment in early life has a profound influence on the development of the social brain (Champagne and Curley, 2005) and the subsequent expression of social behaviors in adulthood (Fleming et al., 1999; Veenema, 2012; Branchi et al., 2013). Manipulations of the neonatal social environment are widely used experimental procedures in rodents and primates to investigate the developmental consequences of stress, childhood adversity, or trauma during early life. The use of such animal models 
has proven successful in advancing our understanding of how mother-infant and peer interactions, for instance, alter developmental trajectories. Alterations in aggressive and anxiety traits have been recognized in rats that were repeatedly isolated from their mother (maternal separation; MS) and their littermates (early deprivation; ED) during the neonatal period (Biagini et al., 1998; Marmendal et al., 2006; Rees et al., 2006) or post-weaning period (Toth et al., 2012). These dispositions arise presumably from abnormalities in the stress response system comprising the corticolimbic circuit and the hypothalamic-pituitary-adrenal (HPA) axis (Pryce et al., 2011; Birnie et al., 2013; Rincon-Cortes and Sullivan, 2014), in which its developmental programming is susceptible to stressful stimuli during critical periods in life. This observation is supported epidemiologically, with parental loss, physical abuse, sexual abuse, and neglect having been shown to be important for determining developmental outcomes, including neuroendocrine stress response (Laurent et al., 2014). Other environmental factors known to modify affective or social behavior in maturity include perinatal exposure to toxic chemicals (Disney et al., 2008; Haijima et al., 2010; Xu et al., 2012; Hamilton et al., 2014; Kiryanova and Dyck, 2014), and some of these chemicalinduced behavioral abnormalities are associated with alterations in the stress response system (Glavas et al., 2007; Poimenova et al., 2010).

It is hypothesized that early life environment, particularly one that affects the neuroendocrine stress response system, shapes the neural basis of social behavior, which in turn may contribute to the hierarchical status within a group later in life. However, the contribution of the early-life environment to social dominance is largely unknown. Here we describe two mouse models that exhibit subordinate behavior in adulthood as a result of insults during development: neonatal ED manipulation (Benner et al., 2014) and perinatal exposure to an environmental pollutant, dioxin (Endo et al., 2012). We will also discuss the possible neurological foundations underlying social dominance.

\section{Methods for Assessing Dominance}

Social dominance in wild animals is often determined by field observations (Gesquiere et al., 2011). Although replicating a true natural setting is a challenge in a laboratory-based experimental setup, machine-based behavioral phenotyping technologies specialized for monitoring colonies of mice have been developed (Freund et al., 2013; Ohayon et al., 2013; Weissbrod et al., 2013). They may be developed further in the near future to provide suitable tools for evaluating complex social structures such as hierarchy. Currently, however, a hierarchy is commonly assessed based on a dominant or a subordinate phenotype exhibited by one-to-one competitions, e.g., the tube test (Lindzey et al., 1961), the social interaction test (Coura et al., 2013), the urine-marking assay (Desjardins et al., 1973; Drickamer, 2001), the dominant-submissive relationship (DSR) paradigm (Feder et al., 2010), and the resident intruder test (Kaliste-Korhonen and Eskola, 2000). In other words, dominance hierarchies have been studied under the premise that dominant-subordinate relationships between pairs of individuals account for the overall hierarchical structure of a colony. Because no more than two mice can be tested at a time in the above paradigms, the efficiency of generating rankings within the tested colony is greatly compromised.

We have recently established a behavioral test protocol for quantifying dominance behavior in group-housed mice (Endo et al., 2012) using a commercially available machine-based behavioral phenotyping system called an IntelliCage apparatus (Galsworthy et al., 2005) (Figure 1A). The IntelliCage-based competition task is contextually similar to the paradigm presented in the visible burrow system established for rats (Blanchard et al., 1988, 1995). In both systems, the individual animal's behaviors are assessed in a social environment, and a group of mice is subjected to a social stress resulting from competition for resources. In the visible burrow system, animals are classified as dominant or subordinate by agonistic interactions (attacks and guarding behavior) manually scored by video monitoring. In the IntelliCage-based competition task, the mice that occupy the limited resource sites at the beginning of the session are classified as dominants, while those that fail to achieve access to the resource sites are classified as subordinates.

In the competition task protocol, mice are deprived of water throughout the day, except during the $3 \mathrm{~h}$ session period between 2200 and 0100 , to establish motivation for accessing the corner chambers for water as a reward (Figure 1B). Once a session begins, over a dozen mice compete against each other, as in a game of musical chairs, for the water in the limited access sites situated in the four corner chambers (Figure 1C). Because of the daylong water deprivation, the competition is greatest at the beginning of the session (approximately 22:00-22:05), and the occupancy of the corner chambers is monopolized by the dominant mice. During the following period (approximately 22:05-22:10), the subordinate mice can gain access to the corner chambers. After a while, the intense competition subsides. In this system, the mode of competition can be manipulated by adjusting the number of mice in a cage and the number of available corner chambers (Figure 1D).

\section{Competitive Subordinance in Group-Housed Mice}

We have previously shown that ED mice, generated by isolating neonates from their mother and littermates for $3 \mathrm{~h}$ per day for the first 2 weeks after birth (Pryce and Feldon, 2003; Millstein et al., 2006), exhibit subordinate behavior in the IntelliCagebased competition task (Benner et al., 2014). We have also shown that mice perinatally exposed to a low dose of dioxin, a ubiquitous environmental pollutant, exhibit subordinate behavior in adulthood (Endo et al., 2012). In both cases, the subordinate behavior was attributable to developmental abnormality that occurred during early life, long before the time at which the behavioral tests were conducted.

The subordinate behaviors were persistently present throughout the competition task sessions for both the ED mice and the mice perinatally exposed to dioxin. A reasonable hypothesis is that the subordinate mice's motivation toward the reward 


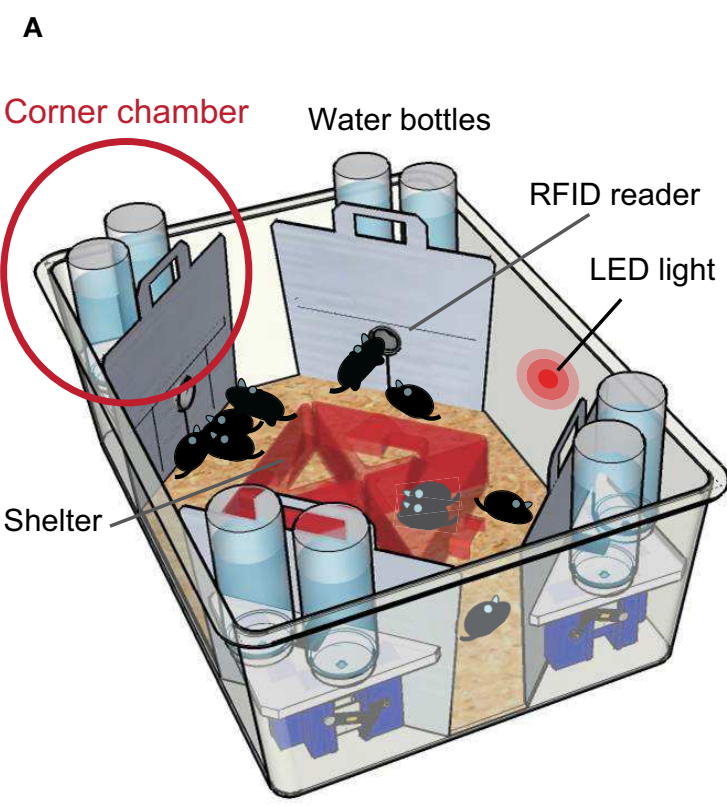

FIGURE 1 | Intelli-Cage-based competition task protocol. (A) An IntelliCage apparatus comprising a large cage $[55 \times 37.5 \times 20.5 \mathrm{~cm}(\mathrm{w} \times \mathrm{d} \times$ h)] equipped with four corner chambers $[15 \times 15 \times 21 \mathrm{~cm}]$ controlled by a computer. Each of these chambers holds two water bottles and functions as a fully automated operational unit. A radiofrequency identification (RFID) device reader is located at the entrance of each chamber and enables the IntelliCage software to record the entry and exit time of each individual resident mouse, given that all resident mice have been tagged by the subcutaneous implantation of RFID microchips. An entry to each chamber is physically restricted to a single mouse at any given time. Inside the chamber, there is a motorized door in front of each water bottle nozzle. The opening and closing of the door are programmable and can be uniquely assigned for each mouse. For instance, the door can detect the nose poking behavior of a mouse, which can be used to initiate opening, and closing can be programmed by time. (B) Mice are deprived of water throughout the day, except during the session period between 2200 and $0100 \mathrm{~h}$. Session periods are cued by an LED light on the wall of the IntelliCage, and mice are
B
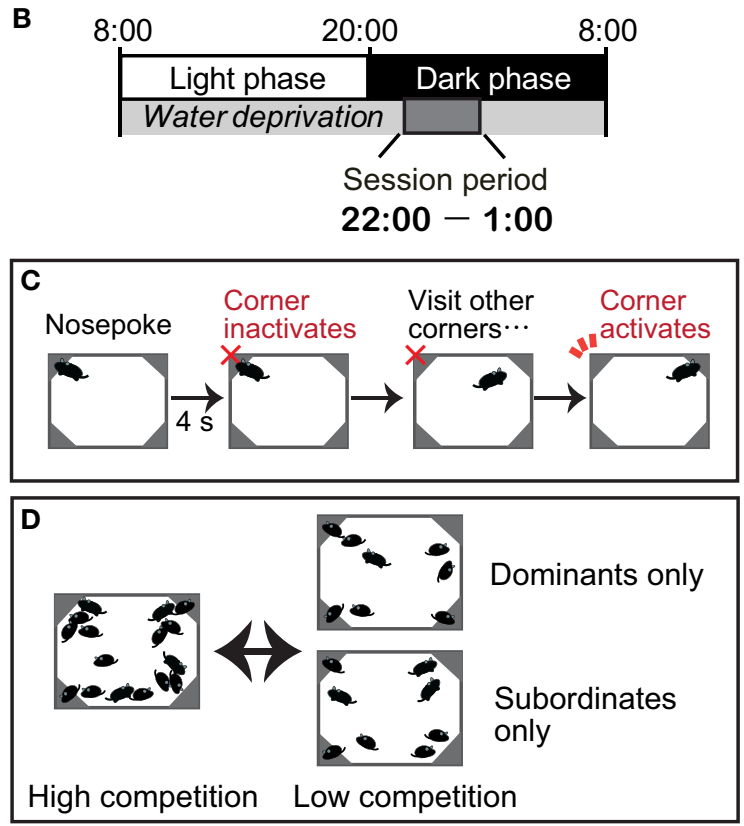

thoroughly trained to learn the cue. (C) Inside the chamber, a mouse uses its nose to poke either of the two doors to open it for accessing the water nozzle. The activated door is programmed to stay open for $4 \mathrm{~s}$. After the door shuts, the chamber becomes inactivated for that mouse, which must go to a different corner chamber for another reward. The task protocol is thus programmed to prevent any single mouse from persistently occupying one corner chamber for an indefinite time. The occupancy of the corner chambers is measured by dwell time or visit frequency. (D) The experimental group composition as well as the degree of competition can be flexibly determined by adjusting the density of animals within an apparatus. Assessment of the motivation level toward reward can be achieved by dividing the dominants and subordinates into two separate cages for several days. If their visiting patterns overlap, it may be regarded as a clear indication that the motivation of the subordinate mice for drinking water is not different from that of the dominants. After the motivational level of the subordinates has been confirmed, all the mice can be combined again to confirm whether the peak number of visits in the subordinates declines once again. is lower than that of the dominant mice, and accordingly accounts for decreased occupancy of the corner chambers. In the IntelliCage-based competition task, the level of motivation can be assessed by several means as follows: (i) evaluating the water consumption under a basal, non-competitive condition; (ii) evaluating the total dwell time and frequency of visits made within the session. If all of the mice have an equal level of motivation, an equal duration and number of total visits would be expected, although the timing of the visits may differ depending on the dominance behavior; and (iii) evaluating the subordinate mice's motivation for drinking in the absence of dominant mice (Figure 1D).

It is notable that in both mice models, the subordinate mice did not differ from the dominant mice in terms of water consumption per day and motivation for drinking water at the beginning of the water-availability period. Furthermore, the removal of the dominant mice from the cage ameliorates the subordinate mice's visiting behavior. Taken together, these observations emphasize that social environment plays an imperative role in determining the behavior of these mice, and that the early life environment can alter the vulnerability to social-emotional challenges in adulthood. The subordinate behavior may reflect a social-phobic temperament, resembling that of social anxiety disorder or autism spectrum disorder (ASD) in humans. In contrast, an abnormality in competitive dominance may be manifested in the hyperdominance of individuals, a behavior considered suggestive of conduct disorder observed in humans.

\section{Possible Neural Basis of Dominance Behavior}

The medial prefrontal cortex (mPFC) is one of the major brain regions associated with the dominant-subordinate phenotype assessed by the IntelliCage-based competition task. This observation is consistent with previous reports on animals (Gesquiere 
et al., 2011; Wang et al., 2011) and humans (Zink et al., 2008; Freeman et al., 2009). In ED mice, the expression of the Map2 gene, which is considered to be involved in dendritic remodeling associated with synaptic plasticity, is significantly reduced in $\mathrm{mPFC}$, and a significant correlation is observed between the dominance level and Map2 expression level (Benner et al., 2014). This observation is consistent with a previous report describing a significant association between dominance rank and synaptic efficiency in mPFC in mice (Wang et al., 2011). The mPFC of mice born to dams perinatally exposed to a low dose of dioxin showed reduced expression of the immediate early genes (IEGs), c-Fos and Arc, indicating reduced neuronal activity (Endo et al., 2012). The mPFC is considered to undergo experience-dependent changes. For example, social experiencerelated reductions in dendritic spine density and IEG expression in $\mathrm{mPFC}$ were found in rats exposed to ethanol during gestation (Hamilton et al., 2010). The prefrontal acetylcholine system has recently been shown to be involved in dominance behavior characterized by the social interaction test (Coura et al., 2013). In addition to the relationship of $\mathrm{MPFC}$ with the dominance trait, fMRI studies of humans showed that $\mathrm{mPFC}$ is associated with social phobia (Blair et al., 2010) and social anxiety disorders (Shang et al., 2014).

The amygdala is another brain region in which ED mice and dioxin-exposed mice share similar neurological characteristics (Endo et al., 2012; Benner et al., 2014). In both cases, c-Fos expression was elevated in the basolateral amygdala (BLA), and its expression level was inversely correlated with dominance rank in the ED study. BLA plays important regulating roles in anticipatory anxiety (Savonenko et al., 1999), social cue processing (Adolphs, 2001; Truitt et al., 2007), and stimulus-reward processing (Murray, 2007). Its function is strongly affected by early life stress both in humans (Marusak et al., 2014; Suzuki et al., 2014) and rodents (Caldji et al., 1998; Berman et al., 2014; Tzanoulinou et al., 2014). Amygdala activity habituates to repeated presentations of social stimuli in healthy subjects (Wedig et al., 2005), suggesting its role in social adaptation. However, abnormal BLA excitation has been suggested to occur in social anxiety disorder and ASD (Truitt et al., 2007; Kleinhans et al., 2009). BLA is particularly sensitive to early life stress and has a critical window (Koppensteiner et al., 2014). Children who experienced early life stress were observed to have enhanced amygdala activity (Maheu et al., 2010; Tottenham, 2012; Gee et al., 2013). Importantly, functional connectivity between the mPFC and amygdala has been recognized (Likhtik et al., 2005, 2014). The integrity of the mPFCamygdala circuit is hypothesized to be a critical determinant of the self-regulation of socio-emotional behavior in response to one's social environment, characteristically disrupted in patients with ASD (Bachevalier and Loveland, 2006).

Social recognition and social memory are thought to contribute to the maintenance of the dominance hierarchy. Social memory, distinct from other types of memory, involves a special neural circuit relaying signals from olfactory social cues (e.g., pheromones) to the medial amygdala (MeA), which innervates the lateral septum (LS) and the bed nucleus of the stria terminalis (BNST). The neural circuit that involves the regions listed above is highly stress-responsive and regulates aggressive behavior (Ferguson et al., 2002; Nelson and Trainor, 2007). The neuropeptides vasopressin and oxytocin regulate social behavior and stress responses, and the role of oxytocin receptors in the long-term establishment of dominance hierarchies has been reported (Timmer et al., 2011).

\section{Stress and Dominance}

An association between dominance behavior and neuroendocrine stress response has been an intriguing subject in the field of social neuroscience. Experiencing dominance hierarchies can be stressful to both subordinate and dominant individuals (Blanchard et al., 1995; Gesquiere et al., 2011), and neuroendocrine characteristics associated with the stress of being subordinate have been reviewed (Blanchard et al., 1993). In general, social subordinance is associated with hypercortisolism or feedback resistance (Sapolsky et al., 1997), whereas glucocorticoid signaling is involved in agonistic behaviors, including dominance, under conditions when hierarchy has not been established. Corticosterone administration affects aggressive behavior in resident intruder conflicts (Mikics et al., 2004), but does not affect intracolony aggression in colonies that have already been established to have stable social relationships (Mikics et al., 2007). However, glucocorticoids are thought to play a critical role in the establishment of a dominance hierarchy and in the longterm maintenance of dominant-subordinate relationships. Rats exposed to stresses just before the first social encounter tend to become subordinate toward unfamiliar rats that were not exposed to the same stresses and have similar attributes, such as body weight and trait anxiety; and the dominant-subordinate relationship established between a given pair of rats persists over time (Cordero and Sandi, 2007). It is thus implied that sensitivity and reactivity toward the stress response (HPA axis function and regulation) have a major effect not only on determining the hierarchical phenotype at the time of a first social encounter but also on the long-term maintenance of an individual's dominance behavior.

Importantly, the integrity of the neuroendocrine stress response system can be modulated by external insults such as disrupted neonatal social environment and perinatal exposure to a neurotoxic chemical. Accumulating reports show that the HPA axis is programmed, at least in part, by early-life events (Matthews, 2002). In particular, early-life stress can modify the development of HPA functioning and thereby influence behavior as well as susceptibility to certain diseases in adulthood. In nonhuman primates, prenatal stress, experimentally induced by gestational glucocorticoid exposure, influences social play behavior and HPA axis function (Mustoe et al., 2014). Similarly, hyperaggressive traits have been observed with repeated corticosterone administration to peripubertal rats (Veenit et al., 2013).

Previous studies have shown the effects of ED on behavior in adulthood and HPA axis function (Ruedi-Bettschen et al., 2004, 2006; Marmendal et al., 2006; Rees et al., 2006, 2008). However, the developmental toxicity to the neuroendocrine stress response system of perinatal dioxin exposure has not been thoroughly assessed in mice. The HPA axis manifests acute toxicity upon dioxin exposure in primates (Shridhar et al., 2001) and 
rats (Balk and Piper, 1984; Bestervelt et al., 1993). For example, TCDD administration increases adrenal sensitivity to adrenocorticotropic hormone (ACTH) in adult rats (Dibartolomeis et al., 1987). In addition, pituitary gland toxicities have been shown in vivo (Moore et al., 1989) and in vitro, resulting in, for example, increases in the gene expression of the ACTH precursor proopiomelanocortin (POMC) (Bestervelt et al., 1998; Huang et al., 2000, 2002) and ACTH and corticosterone secretion (Pitt et al., 2000). Recent studies have shown that prenatal dioxin exposure reduces the expression of pituitary hormones (Takeda et al., 2014) and decreases the circulating level of corticosterone in pregnant dams and their fetuses. This response causes in utero growth retardation that can be rescued by supplying corticosterone to dioxin-exposed dams (Hattori et al., 2014). These findings suggest that the HPA axis is disrupted in the perinatal dioxin exposure model.

\section{Conclusions}

We have described two cases in which early-life environmental manipulations have induced alterations in dominance behavior. These studies extend previous observations that social behavior can be shaped by environment, and show that competitive dominance is a robust, reliable, and also highly sensitive trait allowing the evaluation of the effects of developmental insults

\section{References}

Adolphs, R. (2001). The neurobiology of social cognition. Curr. Opin. Neurobiol. 11, 231-239. doi: 10.1016/S0959-4388(00)00202-6

Akbaripasand, A., Krkosek, M., Lokman, P. M., and Closs, G. P. (2014). Does social status within a dominance hierarchy mediate individual growth, residency and relocation? Oecologia 176, 771-779. doi: 10.1007/s00442-014-3038-z

Babri, S., Doosti, M. H., and Salari, A. A. (2014). Strain-dependent effects of prenatal maternal immune activation on anxiety- and depression-like behaviors in offspring. Brain Behav. Immun. 37, 164-176. doi: 10.1016/j.bbi.2013.12.003

Bachevalier, J., and Loveland, K. A. (2006). The orbitofrontal-amygdala circuit and self-regulation of social-emotional behavior in autism. Neurosci. Biobehav. Rev. 30, 97-117. doi: 10.1016/j.neubiorev.2005.07.002

Balk, J. L., and Piper, W. N. (1984). Altered blood levels of corticosteroids in the rat after exposure to 2,3,7,8-tetrachlorodibenzo-p-dioxin. Biochem. Pharmacol. 33, 2531-2534. doi: 10.1016/0006-2952(84)90732-9

Benner, S., Endo, T., Endo, N., Kakeyama, M., and Tohyama, C. (2014). Early deprivation induces competitive subordinance in C57BL/6 male mice. Physiol. Behav. 137, 42-52. doi: 10.1016/j.physbeh.2014.06.018

Berman, A. K., Lott, R. B., and Donaldson, S. T. (2014). Periodic maternal deprivation may modulate offspring anxiety-like behavior through mechanisms involving neuroplasticity in the amygdala. Brain Res. Bull. 101, 7-11. doi: 10.1016/j.brainresbull.2013.12.005

Bestervelt, L. L., Pitt, J. A., Nolan, C. J., Cai, Y., Piper, D. W., Dybowski, J. A., et al. (1998). In vitro 2,3,7,8-tetrachlorodibenzo-p-dioxin interference with the anterior pituitary hormone adrenocorticortropin. Toxicol. Sci. 44, 107-115.

Bestervelt, L. L., Pitt, J. A., Nolan, C. J., and Piper, W. N. (1993). TCDD alters pituitary-adrenal function. II: evidence for decreased bioactivity of ACTH. Neurotoxicol. Teratol. 15, 371-376. doi: 10.1016/0892-0362(93)90053-Q

Biagini, G., Pich, E. M., Carani, C., Marrama, P., and Agnati, L. F. (1998). Postnatal maternal separation during the stress hyporesponsive period enhances the adrenocortical response to novelty in adult rats by affecting feedback regulation in the CA1 hippocampal field. Int. J. Dev. Neurosci. 16, 187-197. doi: 10.1016/S0736-5748(98)00019-7 on neuroendocrinological systems in mice. Dominance is presumably more complex than one-to-one competition and is highly dependent on the social environment. The IntelliCagebased competition task permits the determination of the individual mouse's level of dominance in a group, given that the task is presented simultaneously to over a dozen mice in a single apparatus. Thus, it is considered that the dominance in this test represents not merely competitive but social dominance. In addition, an evaluation of the correlation between the level of dominance and the gene expression patterns in the ED model cannot be achieved by other standardized behavioral assays used to investigate the social status in rodents.

\section{Author Contributions}

SB, TE, MK, and CT wrote the paper.

\section{Acknowledgments}

This study was supported in part by JSPS Research Fellowships for Young Scientists (SB and TE), JSPS Kakenhi (26241016 to MK and 24221003 to CT), the Health and Labor Sciences Research Grant from MHLW (MK), and by MEXT SRPBS (10036021 to CT).

Birnie, A. K., Taylor, J. H., Cavanaugh, J., and French, J. A. (2013). Quality of maternal and paternal care predicts later stress reactivity in the cooperatively-breeding marmoset (Callithrix geoffroyi). Psychoneuroendocrinology 38, 3003-3014. doi: 10.1016/j.psyneuen.2013.08.011

Blair, K. S., Geraci, M., Hollon, N., Otero, M., Devido, J., Majestic, C., et al. (2010). Social norm processing in adult social phobia: atypically increased ventromedial frontal cortex responsiveness to unintentional (embarrassing) transgressions. Am. J. Psychiatry 167, 1526-1532. doi: 10.1176/appi.ajp.2010.09121797

Blanchard, D. C., Sakai, R. R., McEwen, B., Weiss, S. M., and Blanchard, R. J. (1993). Subordination stress: behavioral, brain, and neuroendocrine correlates. Behav. Brain Res. 58, 113-121. doi: 10.1016/0166-4328(93)90096-9

Blanchard, D. C., Spencer, R. L., Weiss, S. M., Blanchard, R. J., McEwen, B., and Sakai, R. R. (1995). Visible burrow system as a model of chronic social stress: behavioral and neuroendocrine correlates. Psychoneuroendocrinology 20, 117-134. doi: 10.1016/0306-4530(94)E0045-B

Blanchard, R. J., Flannelly, K. J., and Blanchard, D. C. (1988). Life-span studies of dominance and aggression in established colonies of laboratory rats. Physiol. Behav. 43, 1-7. doi: 10.1016/0031-9384(88)90089-3

Branchi, I., Curley, J. P., D'Andrea, I., Cirulli, F., Champagne, F. A., and Alleva, E. (2013). Early interactions with mother and peers independently build adult social skills and shape BDNF and oxytocin receptor brain levels. Psychoneuroendocrinology 38, 522-532. doi: 10.1016/j.psyneuen.2012.07.010

Braw, Y., Malkesman, O., Dagan, M., Bercovich, A., Lavi-Avnon, Y., Schroeder, M., et al. (2006). Anxiety-like behaviors in pre-pubertal rats of the Flinders Sensitive Line (FSL) and Wistar-Kyoto (WKY) animal models of depression. Behav. Brain Res. 167, 261-269. doi: 10.1016/j.bbr.2005.09.013

Caldji, C., Tannenbaum, B., Sharma, S., Francis, D., Plotsky, P. M., and Meaney, M. J. (1998). Maternal care during infancy regulates the development of neural systems mediating the expression of fearfulness in the rat. Proc. Natl. Acad. Sci. U.S.A. 95, 5335-5340. doi: 10.1073/pnas.95.9.5335

Champagne, F. A., and Curley, J. P. (2005). How social experiences influence the brain. Curr. Opin. Neurobiol. 15, 704-709. doi: 10.1016/j.conb.2005.10.001

Chase, I. D., Tovey, C., Spangler-Martin, D., and Manfredonia, M. (2002). Individual differences versus social dynamics in the formation of animal 
dominance hierarchies. Proc. Natl. Acad. Sci. U.S.A. 99, 5744-5749. doi: 10.1073/pnas.082104199

Cordero, M. I., and Sandi, C. (2007). Stress amplifies memory for social hierarchy. Front. Neurosci. 1, 175-184. doi: 10.3389/neuro.01.1.1.013.2007

Coura, R. S., Cressant, A., Xia, J., de Chaumont, F., Olivo-Marin, J. C., Pelloux, Y., et al. (2013). Nonaggressive and adapted social cognition is controlled by the interplay between noradrenergic and nicotinic receptor mechanisms in the prefrontal cortex. FASEB J. 27, 4343-4354. doi: 10.1096/fj.13-231084

Desjardins, C., Maruniak, J. A., and Bronson, F. H. (1973). Social rank in house mice: differentiation revealed by ultraviolet visualization of urinary marking patterns. Science 182, 939-941. doi: 10.1126/science.182.4115.939

Dewsbury, D. A. (1982). Dominance rank, copulatory behavior, and differential reproduction. Q. Rev. Biol. 57, 135-159. doi: 10.1086/412672

Dibartolomeis, M. J., Moore, R. W., Peterson, R. E., Christian, B. J., and Jefcoate, C. R. (1987). Altered regulation of adrenal steroidogenesis in 2,3,7,8tetrachlorodibenzo-p-dioxin-treated rats. Biochem. Pharmacol. 36, 59-67. doi: 10.1016/0006-2952(87)90382-0

Disney, E. R., Iacono, W., McGue, M., Tully, E., and Legrand, L. (2008). Strengthening the case: prenatal alcohol exposure is associated with increased risk for conduct disorder. Pediatrics 122, e1225-e1230. doi: 10.1542/peds.2008-1380

Drickamer, L. C. (2001). Urine marking and social dominance in male house mice (Mus musculus domesticus). Behav. Processes 53, 113-120. doi: 10.1016/S03766357(00)00152-2

Endo, T., Kakeyama, M., Uemura, Y., Haijima, A., Okuno, H., Bito, H., et al. (2012). Executive function deficits and social-behavioral abnormality in mice exposed to a low dose of dioxin in utero and via lactation. PLoS ONE 7:e50741. doi: 10.1371/journal.pone.0050741

Feder, Y., Nesher, E., Ogran, A., Kreinin, A., Malatynska, E., Yadid, G., et al. (2010). Selective breeding for dominant and submissive behavior in Sabra mice. J. Affect. Disord. 126, 214-222. doi: 10.1016/j.jad.2010.03.018

Ferguson, J. N., Young, L. J., and Insel, T. R. (2002). The neuroendocrine basis of social recognition. Front. Neuroendocrinol. 23, 200-224. doi: 10.1006/frne.2002.0229

Fleming, A. S., O'Day, D. H., and Kraemer, G. W. (1999). Neurobiology of motherinfant interactions: experience and central nervous system plasticity across development and generations. Neurosci. Biobehav. Rev. 23, 673-685.

Freeman, J. B., Rule, N. O., Adams, R. B. Jr., and Ambady, N. (2009). Culture shapes a mesolimbic response to signals of dominance and subordination that associates with behavior. Neuroimage 47, 353-359. doi: 10.1016/j.neuroimage.2009.04.038

Freund, J., Brandmaier, A. M., Lewejohann, L., Kirste, I., Kritzler, M., Kruger, A., et al. (2013). Emergence of individuality in genetically identical mice. Science 340, 756-759. doi: 10.1126/science.1235294

Galsworthy, M. J., Amrein, I., Kuptsov, P. A., Poletaeva, I. I., Zinn, P., Rau, A., et al. (2005). A comparison of wild-caught wood mice and bank voles in the Intellicage: assessing exploration, daily activity patterns and place learning paradigms. Behav. Brain Res. 157, 211-217. doi: 10.1016/j.bbr.2004.06.021

Gee, D. G., Gabard-Durnam, L. J., Flannery, J., Goff, B., Humphreys, K. L., Telzer, E. H., et al. (2013). Early developmental emergence of human amygdalaprefrontal connectivity after maternal deprivation. Proc. Natl. Acad. Sci. U.S.A. 110, 15638-15643. doi: 10.1073/pnas. 1307893110

Gesquiere, L. R., Learn, N. H., Simao, M. C., Onyango, P. O., Alberts, S. C., and Altmann, J. (2011). Life at the top: rank and stress in wild male baboons. Science 333, 357-360. doi: 10.1126/science. 1207120

Glavas, M. M., Ellis, L., Yu, W. K., and Weinberg, J. (2007). Effects of prenatal ethanol exposure on basal limbic-hypothalamic-pituitary-adrenal regulation: role of corticosterone. Alcohol. Clin. Exp. Res. 31, 1598-1610. doi: 10.1111/j.1530-0277.2007.00460.x

Haijima, A., Endo, T., Zhang, Y., Miyazaki, W., Kakeyama, M., and Tohyama, C. (2010). In utero and lactational exposure to low doses of chlorinated and brominated dioxins induces deficits in the fear memory of male mice. Neurotoxicology 31, 385-390. doi: 10.1016/j.neuro.2010.04.004

Hamilton, D. A., Barto, D., Rodriguez, C. I., Magcalas, C. M., Fink, B. C., Rice, J. P., et al. (2014). Effects of moderate prenatal ethanol exposure and age on social behavior, spatial response perseveration errors and motor behavior. Behav. Brain Res. 269, 44-54. doi: 10.1016/j.bbr.2014.04.029

Hamilton, D. A., Candelaria-Cook, F. T., Akers, K. G., Rice, J. P., Maes, L. I., Rosenberg, M., et al. (2010). Patterns of social-experience-related c-fos and Arc expression in the frontal cortices of rats exposed to saccharin or moderate levels of ethanol during prenatal brain development. Behav. Brain Res. 214, 66-74. doi: 10.1016/j.bbr.2010.05.048

Hattori, Y., Takeda, T., Fujii, M., Taura, J., Ishii, Y., and Yamada, H. (2014). Dioxininduced fetal growth retardation: the role of a preceding attenuation in the circulating level of glucocorticoid. Endocrine 47, 572-580. doi: 10.1007/s12020014-0257-3

Huang, P., Ceccatelli, S., Håkansson, H., Grandison, L., and Rannug, A. (2002). Constitutive and TCDD-induced expression of ah receptor-responsive genes in the pituitary. Neurotoxicology 23, 783-793. doi: 10.1016/S0161-813X(02) 00040-2

Huang, P., Rannug, A., Ahlbom, E., Hakansson, H., and Ceccatelli, S. (2000). Effect of 2,3,7,8-tetrachlorodibenzo-p-dioxin on the expression of cytochrome $\mathrm{P} 450$ $1 \mathrm{~A} 1$, the aryl hydrocarbon receptor, and the aryl hydrocarbon receptor nuclear translocator in rat brain and pituitary. Toxicol. Appl. Pharmacol. 169, 159-167. doi: 10.1006/taap.2000.9064

Kaliste-Korhonen, E., and Eskola, S. (2000). Fighting in NIH/S male mice: consequences for behaviour in resident-intruder tests and physiological parameters. Lab. Anim. 34, 189-198. doi: 10.1258/002367700780457626

Kiryanova, V., and Dyck, R. H. (2014). Increased aggression, improved spatial memory, and reduced anxiety-like behaviour in adult male mice exposed to fluoxetine early in life. Dev. Neurosci. 36, 396-408. doi: 10.1159/ 000363102

Kleinhans, N. M., Johnson, L. C., Richards, T., Mahurin, R., Greenson, J., Dawson, G., et al. (2009). Reduced neural habituation in the amygdala and social impairments in autism spectrum disorders. Am. J. Psychiatry 166, 467-475. doi: 10.1176/appi.ajp.2008.07101681

Koppensteiner, P., Aizawa, S., Yamada, D., Kabuta, T., Boehm, S., Wada, K., et al. (2014). Age-dependent sensitivity to glucocorticoids in the developing mouse basolateral nucleus of the amygdala. Psychoneuroendocrinology 46, 64-77. doi: 10.1016/j.psyneuen.2014.04.007

Laurent, H. K., Neiderhiser, J. M., Natsuaki, M. N., Shaw, D. S., Fisher, P. A., Reiss, D., et al. (2014). Stress system development from age 4.5 to 6 : family environment predictors and adjustment implications of HPA activity stability versus change. Dev. Psychobiol. 56, 340-354. doi: 10.1002/dev.21103

Likhtik, E., Pelletier, J. G., Paz, R., and Pare, D. (2005). Prefrontal control of the amygdala. J. Neurosci. 25, 7429-7437. doi: 10.1523/JNEUROSCI.2314-05.2005

Likhtik, E., Stujenske, J. M. A., Topiwala, M., Harris, A. Z., and Gordon, J. A. (2014). Prefrontal entrainment of amygdala activity signals safety in learned fear and innate anxiety. Nat. Neurosci. 17, 106-113. doi: 10.1038/nn.3582

Lindzey, G., Winston, H., and Manosevitz, M. (1961). Social dominance in inbred mouse strains. Nature 191, 474-476. doi: 10.1038/191474a0

Maheu, F. S., Dozier, M., Guyer, A. E., Mandell, D., Peloso, E., Poeth, K., et al. (2010). A preliminary study of medial temporal lobe function in youths with a history of caregiver deprivation and emotional neglect. Cogn. Affect. Behav. Neurosci. 10, 34-49. doi: 10.3758/CABN.10.1.34

Malatynska, E., and Knapp, R. J. (2005). Dominant-submissive behavior as models of mania and depression. Neurosci. Biobehav. Rev. 29, 715-737. doi: 10.1016/j.neubiorev.2005.03.014

Malkesman, O., Maayan, R., Weizman, A., and Weller, A. (2006). Aggressive behavior and HPA axis hormones after social isolation in adult rats of two different genetic animal models for depression. Behav. Brain Res. 175, 408-414. doi: 10.1016/j.bbr.2006.09.017

Marmendal, M., Eriksson, C. J., and Fahlke, C. (2006). Early deprivation increases exploration and locomotion in adult male Wistar offspring. Pharmacol. Biochem. Behav. 85, 535-544. doi: 10.1016/j.pbb.2006.10.005

Marusak, H. A., Martin, K. R., Etkin, A., and Thomason, M. E. (2014). Childhood trauma exposure disrupts the automatic regulation of emotional processing. Neuropsychopharmacology. doi: 10.1038/npp.2014.311. [Epub ahead of print].

Matthews, S. G. (2002). Early programming of the hypothalamo-pituitaryadrenal axis. Trends Endocrinol. Metab. 13, 373-380. doi: 10.1016/S10432760(02)00690-2

Mikics, E., Barsy, B., and Haller, J. (2007). The effect glucocorticoids on aggressiveness in established colonies of rats. Psychoneuroendocrinology 32, 160-170. doi: 10.1016/j.psyneuen.2006.12.002

Mikics, E., Kruk, M. R., and Haller, J. (2004). Genomic and non-genomic effects of glucocorticoids on aggressive behavior in male rats. Psychoneuroendocrinology 29, 618-635. doi: 10.1016/S0306-4530(03)00090-8 
Millstein, R. A., Ralph, R. J., Yang, R. J., and Holmes, A. (2006). Effects of repeated maternal separation on prepulse inhibition of startle across inbred mouse strains. Genes Brain Behav. 5, 346-354. doi: 10.1111/j.1601-183X.2005.00172.x

Moore, R. W., Parsons, J. A., Bookstaff, R. C., and Peterson, R. E. (1989). Plasma concentrations of pituitary hormones in 2,3,7,8-tetrachlorodibenzo-p-dioxintreated male rats. J. Biochem. Toxicol. 4, 165-172. doi: 10.1002/jbt.2570040305

Murray, E. A. (2007). The amygdala, reward and emotion. Trends Cogn. Sci. 11, 489-497. doi: 10.1016/j.tics.2007.08.013

Mustoe, A. C., Taylor, J. H., Birnie, A. K., Huffman, M. C., and French, J. A. (2014). Gestational cortisol and social play shape development of marmosets' HPA functioning and behavioral responses to stressors. Dev. Psychobiol. 56, 1229-1243. doi: 10.1002/dev.21203

Nelson, R. J., and Trainor, B. C. (2007). Neural mechanisms of aggression. Nat. Rev. Neurosci. 8, 536-546. doi: 10.1038/nrn2174

Ohayon, S., Avni, O., Taylor, A. L., Perona, P., and Roian Egnor, S. E. (2013). Automated multi-day tracking of marked mice for the analysis of social behaviour. J. Neurosci. Methods 219, 10-19. doi: 10.1016/j.jneumeth.2013.05.013

Pitt, J. A., Buckalew, A. R., House, D. E., and Abbott, B. D. (2000). Adrenocorticotropin $(\mathrm{ACTH})$ and corticosterone secretion by perifused pituitary and adrenal glands from rodents exposed to 2,3,7, 8-tetrachlorodibenzo-p-dioxin (TCDD). Toxicology 151, 25-35. doi: 10.1016/S0300-483X(00)00257-2

Poimenova, A., Markaki, E., Rahiotis, C., and Kitraki, E. (2010). Corticosteroneregulated actions in the rat brain are affected by perinatal exposure to low dose of bisphenol A. Neuroscience 167, 741-749. doi: 10.1016/j.neuroscience.2010.02.051

Pryce, C. R., Aubert, Y., Maier, C., Pearce, P. C., and Fuchs, E. (2011). The developmental impact of prenatal stress, prenatal dexamethasone and postnatal social stress on physiology, behaviour and neuroanatomy of primate offspring: studies in rhesus macaque and common marmoset. Psychopharmacology (Berl) 214, 33-53. doi: 10.1007/s00213-010-1989-2

Pryce, C. R., and Feldon, J. (2003). Long-term neurobehavioural impact of the postnatal environment in rats: manipulations, effects and mediating mechanisms. Neurosci. Biobehav. Rev. 27, 57-71. doi: 10.1016/S0149-7634(03)00009-5

Rees, S. L., Akbari, E., Steiner, M., and Fleming, A. S. (2008). Effects of early deprivation and maternal separation on pup-directed behavior and HPA axis measures in the juvenile female rat. Dev. Psychobiol. 50, 315-321. doi: 10.1002/dev.20292

Rees, S. L., Steiner, M., and Fleming, A. S. (2006). Early deprivation, but not maternal separation, attenuates rise in corticosterone levels after exposure to a novel environment in both juvenile and adult female rats. Behav. Brain Res. 175, 383-391. doi: 10.1016/j.bbr.2006.09.013

Rincon-Cortes, M., and Sullivan, R. M. (2014). Early life trauma and attachment: immediate and enduring effects on neurobehavioral and stress axis development. Front. Endocrinol. (Lausanne) 5:33. doi: 10.3389/fendo.2014.00033

Rowell, T. E. (1974). The concept of social dominance. Behav. Biol. 11, 131-154. doi: 10.1016/S0091-6773(74)90289-2

Ruedi-Bettschen, D., Feldon, J., and Pryce, C. R. (2004). Circadian- and temperature-specific effects of early deprivation on rat maternal care and pup development: short-term markers for long-term effects? Dev. Psychobiol. 45, 59-71. doi: 10.1002/dev.20014

Ruedi-Bettschen, D., Zhang, W., Russig, H., Ferger, B., Weston, A., Pedersen, E. M., et al. (2006). Early deprivation leads to altered behavioural, autonomic and endocrine responses to environmental challenge in adult Fischer rats. Eur. J. Neurosci. 24, 2879-2893. doi: 10.1111/j.1460-9568.2006.05158.x

Sapolsky, R. M., Alberts, S. C., and Altmann, J. (1997). Hypercortisolism associated with social subordinance or social isolation among wild baboons. Arch. Gen. Psychiatry 54, 1137-1143. doi: 10.1001/archpsyc.1997.01830240097014

Savonenko, A., Filipkowski, R. K., Werka, T., Zielinski, K., and Kaczmarek, L. (1999). Defensive conditioning-related functional heterogeneity among nuclei of the rat amygdala revealed by c-Fos mapping. Neuroscience 94, 723-733. doi: 10.1016/S0306-4522(99)00331-0

Shang, J., Fu, Y., Ren, Z., Zhang, T., Du, M., Gong, Q., et al. (2014). The common traits of the ACC and PFC in anxiety disorders in the DSM-5: meta-analysis of voxel-based morphometry studies. PLoS ONE 9:e93432. doi: 10.1371/journal.pone.0093432

Shridhar, S., Farley, A., Reid, R. L., Foster, W. G., and Van Vugt, D. A. (2001). The effect of 2,3,7,8-tetrachlorodibenzo-p-dioxin on corticotrophin-releasing hormone, arginine vasopressin, and pro-opiomelanocortin mRNA levels in the hypothalamus of the cynomolgus monkey. Toxicol. Sci. 63, 181-188. doi: 10.1093/toxsci/63.2.181

Suzuki, H., Luby, J. L., Botteron, K. N., Dietrich, R., McAvoy, M. P., and Barch, D. M. (2014). Early life stress and trauma and enhanced limbic activation to emotionally valenced faces in depressed and healthy children. J. Am. Acad. Child Adolesc. Psychiatry 53, 800.e10-813.e10. doi: 10.1016/j.jaac.2014. 04.013

Takeda, T., Taura, J., Hattori, Y., Ishii, Y., and Yamada, H. (2014). Dioxininduced retardation of development through a reduction in the expression of pituitary hormones and possible involvement of an aryl hydrocarbon receptor in this defect: a comparative study using two strains of mice with different sensitivities to dioxin. Toxicol. Appl. Pharmacol. 278, 220-229. doi: 10.1016/j.taap.2014.04.022

Timmer, M., Cordero, M. I., Sevelinges, Y., and Sandi, C. (2011). Evidence for a role of oxytocin receptors in the long-term establishment of dominance hierarchies. Neuropsychopharmacology 36, 2349-2356. doi: 10.1038/npp. 2011.125

Toth, M., Tulogdi, A., Biro, L., Soros, P., Mikics, E., and Haller, J. (2012). The neural background of hyper-emotional aggression induced by post-weaning social isolation. Behav. Brain Res. 233, 120-129. doi: 10.1016/j.bbr.2012.04.025

Tottenham, N. (2012). Human amygdala development in the absence of speciesexpected caregiving. Dev. Psychobiol. 54, 598-611. doi: 10.1002/dev.20531

Truitt, W., Sajdyk, T., Dietrich, A., Oberlin, B., McDougle, C., and Shekhar, A. (2007). From anxiety to autism: spectrum of abnormal social behaviors modeled by progressive disruption of inhibitory neuronal function in the basolateral amygdala in Wistar rats. Psychopharmacology(Berl) 191, 107-118. doi: 10.1007/s00213-006-0674-y

Tzanoulinou, S., Riccio, O., de Boer, M. W., and Sandi, C. (2014). Peripubertal stress-induced behavioral changes are associated with altered expression of genes involved in excitation and inhibition in the amygdala. Transl. Psychiatry 4, e410. doi: 10.1038/tp.2014.54

Veenema, A. H. (2012). Toward understanding how early-life social experiences alter oxytocin- and vasopressin-regulated social behaviors. Horm. Behav. 61, 304-312. doi: 10.1016/j.yhbeh.2011.12.002

Veenit, V., Cordero, M. I., Tzanoulinou, S., and Sandi, C. (2013). Increased corticosterone in peripubertal rats leads to long-lasting alterations in social exploration and aggression. Front. Behav. Neurosci. 7:26. doi: 10.3389/fnbeh.2013.00026

Wang, F., Zhu, J., Zhu, H., Zhang, Q., Lin, Z., and Hu, H. (2011). Bidirectional control of social hierarchy by synaptic efficacy in medial prefrontal cortex. Science 334, 693-697. doi: 10.1126/science.1209951

Wedig, M. M., Rauch, S. L., Albert, M. S., and Wright, C. I. (2005). Differential amygdala habituation to neutral faces in young and elderly adults. Neurosci. Lett. 385, 114-119. doi: 10.1016/j.neulet.2005.05.039

Weissbrod, A., Shapiro, A., Vasserman, G., Edry, L., Dayan, M., Yitzhaky, A., et al. (2013). Automated long-term tracking and social behavioural phenotyping of animal colonies within a semi-natural environment. Nat. Commun. 4, 2018. doi: 10.1038/ncomms3018

Xu, X., Hong, X., Xie, L., Li, T., Yang, Y., Zhang, Q., et al. (2012). Gestational and lactational exposure to bisphenol-A affects anxiety- and depressionlike behaviors in mice. Horm. Behav. 62, 480-490. doi: 10.1016/j.yhbeh.2012. 08.005

Zink, C. F., Tong, Y., Chen, Q., Bassett, D. S., Stein, J. L., and Meyer-Lindenberg, A. (2008). Know your place: neural processing of social hierarchy in humans. Neuron 58, 273-283. doi: 10.1016/j.neuron.2008.01.025

Conflict of Interest Statement: The authors declare that the research was conducted in the absence of any commercial or financial relationships that could be construed as a potential conflict of interest.

Copyright (c) 2015 Benner, Endo, Kakeyama and Tohyama. This is an open-access article distributed under the terms of the Creative Commons Attribution License (CC $B Y)$. The use, distribution or reproduction in other forums is permitted, provided the original author(s) or licensor are credited and that the original publication in this journal is cited, in accordance with accepted academic practice. No use, distribution or reproduction is permitted which does not comply with these terms. 